\title{
MONETARY Policy, FinANCIAL StABILITY, AND THE DISTRIBUTION OF RISK
}

\author{
EVAN F. KOENIG \\ RESEARCH DEPARTMENT \\ WORKING PAPER 1111
}

Federal Reserve Bank of Dallas 


\title{
Monetary Policy, Financial Stability, and the Distribution of Risk
}

\author{
Evan F. Koenig* \\ Vice President and Senior Policy Advisor \\ Federal Reserve Bank of Dallas \\ Adjunct Professor \\ Southern Methodist University \\ Original: January 2011 \\ This Version: November 2011
}

\begin{abstract}
In an economy in which debt obligations are fixed in nominal terms, but there are otherwise no nominal rigidities, a monetary policy that targets inflation inefficiently concentrates risk, tending to increase the financial distress that accompanies adverse real shocks. Nominalincome targeting spreads risk more evenly across borrowers and lenders, reproducing the equilibrium that one would observe if there were perfect capital markets. Empirically, inflation surprises have no independent influence on measures of financial strain once one controls for shocks to nominal GDP.

* Evan.F.Koenig@dal.frb.org. I have benefitted from the comments of Nathan Balke, John Roberts, John Leahy, and members of the economics department at UNLV. Views expressed are my own, and are not necessarily shared by colleagues at the Federal Reserve Bank of Dallas or elsewhere around the Federal Reserve System.
\end{abstract}




\section{Introduction}

Many financial obligations_-such as loan payments, corporate pension liabilities, and lease payments — are fixed in nominal terms. ${ }^{1}$ The existing literature, going back to Irving Fisher (1933), emphasizes the vulnerability of those with fixed nominal obligations to price-level-induced adverse shocks to their net worth-adverse shocks that are a potential barrier to the extension of credit and, insofar as they lead to defaults or panic asset liquidation, also a potential threat to the smooth functioning of credit markets. These vulnerabilities have been cited as a reason for central banks to adopt price-level or inflation targeting. ${ }^{2}$ However, such thinking is incomplete. Households and firms obligated to make fixed nominal payments are exposed to financial stress whenever nominal income flows deteriorate relative to expectations extant when the obligations were accepted, independent of whether the deterioration is due to lower-than-expected inflation or to lower-thanexpected real income growth. It follows that although purely random variation in the future price level is undesirable, price variation that offsets shocks to real income may serve a useful insurance function. This point is illustrated using a stylized, example economy in which a nominal-income target for monetary policy distributes risk more efficiently across debtors and creditors than does a price-level target. Both policies eliminate purely random price-level variation, but a price target puts the risk due to aggregate real shocks disproportionately onto debtors. ${ }^{3}$ Under a nominal-income target, in contrast, creditors share aggregate-output risk with debtors. In fact, for a standard class of utility functions, nominal-income targeting exactly reproduces the equilibrium that one would observe if there were perfect capital markets.

Previous research has shown that nominal-income targeting can be optimal in representative-agent economies if the path of the money wage is set in advance, but that some

1 "If one thinks about the important sets of contracts in the economy that are set in nominal terms, and which are unlikely to be implicitly insured or indexed against unanticipated price-level changes, financial contracts (such as debt instruments) come immediately to mind.”-Bernanke (1995)

${ }^{2}$ See, for example, Fisher (1933, esp. pp. 346-48), Bernanke (2003), and Crawford et al. (2009). Similarly, Hall (1984) cites the vulnerability of pensioners to unexpected inflation as a reason to favor policy rules that limit price-level uncertainty.

${ }^{3}$ All debt is one-period debt in the model developed in this paper, so that price-level and inflation targeting are equivalent. In a more general setting, the question is whether the central bank ought to minimize price-level uncertainty over whatever horizon nominal debt obligations are fixed or, instead, minimize uncertainty about the path of nominal income over that horizon. 
version of price-level or inflation targeting is generally optimal if it is output prices that are sticky. ${ }^{4}$ The analysis presented here is completely orthogonal to this literature: It does not involve goodsmarket or labor-market pricing frictions in any way. As our most severe economic downturns have been characterized by widespread default on financial obligations and disastrous breakdowns or near breakdowns in lending, an analytical framework that puts debt and the distribution of risk at center stage arguably has something important to say about optimal policy.

The analysis presented in this paper implies that empirical evaluations of the recession role played by nominal debt shouldn't focus narrowly on whether or not there have been significant downside inflation surprises: Financial strains due to fixed nominal obligations can help transmit and amplify negative real shocks, too. Consistent with the theory, empirically it is nominal-income surprises — not inflation surprises — that explain movements in measures of financial stress.

Related work includes papers by Doepke and Schneider (2006a,b) which document the potential size of the shifts in the wealth distribution resulting from unexpected inflation and how these shifts might affect saving and work incentives. There is no discussion of unexpected inflation's potential role in spreading risk due to real shocks. Bohn (2009) analyzes how statecontingent fiscal policy can be used to improve the distribution of risk. There is no money in the economy. An earlier article by Bohn [Bohn (1988)] flips this paper's analysis on its head. The monetary authority is assumed to set the money supply in advance of the current output realization, with the result that the price level moves opposite to output. The fiscal authority optimally chooses to issue at least some nominal debt, to take advantage of the counter-cyclical price level and, so, limit variation in the tax rate. In contrast to Bohn, I look at an economy without a fiscal authority and, following Fisher, take it as given that private debt contracts are written in nominal terms. My goal is not to explain the existence of nominal debt, but to demonstrate that its monetary policy implications are quite different from those that the existing literature takes for granted. ${ }^{5}$

${ }^{4}$ See, for example, Bean (1983), Koenig (1995, 1996, 2005), Ball (1997), McCallum (1997), Rudebusch (2002), and Mankiw and Reis (2002). Nominal-income targeting initially attracted attention as an alternative to money-supply targeting, suitable during periods of significant variation in the velocity of money (Meade 1978, McCallum 1984).

${ }^{5}$ Perhaps people enter into nominal debt contracts because they assume that the monetary authority will pursue a policy that is efficient given such contracts. Only when the monetary authority fails to ratify these expectations do problems arise. 


\section{Formalization of the Risk-Sharing Argument}

Consider a two-period endowment economy with equal numbers of each of two types of household. Households of type 1 each receive real income of $\theta y(1)>0$ in period 1 and $(1-\theta) y(2)$ $\geq 0$ in period 2. Households of type 2 each receive income of $(1-\theta) y(1) \geq 0$ in period 1 and real income of $\theta y(2)>0$ in period 2. With $1 \geq \theta>1 / 2$, period-1 income flows primarily to type- 1 households and period-2 income flows primarily to type-2 households. Period-2 output can take on any of $S$ values, $0<y_{1}(2)<y_{2}(2)<y_{3}(2)<\ldots<y_{S}(2)$, with known probabilities $p_{1}, p_{2}, p_{3}, \ldots, p_{S}$, respectively. The utility of each type-1 household is given by $\mathrm{U}\left(c_{1}(1)\right)+\rho \mathrm{U}\left(c_{1}(2)\right)$, where $c_{1}(1)$ and $c_{1}(2)$ are type-1 consumption in periods 1 and 2, respectively; $0<\rho \leq 1$; and $\mathrm{U}^{\prime}(\bullet)>0, \mathrm{U}^{\prime \prime}(\bullet)<0$, and $\mathrm{U}^{\prime}(c) \rightarrow \infty$ as $c \rightarrow 0$. The utility of type-2 households, similarly, is given by $\mathrm{V}\left(c_{2}(1)\right)+\rho \mathrm{V}\left(c_{2}(2)\right)$, where $c_{2}(1)$ and $c_{2}(2)$ are type-2 consumption in periods 1 and 2, respectively, and where $V^{\prime}(\bullet)>0$, $\mathrm{V}^{\prime \prime}(\bullet)<0$, and $\mathrm{V}^{\prime}(c) \rightarrow \infty$ as $c \rightarrow 0$. Strongest results are derived assuming that households have identical constant-relative-risk-aversion (CRRA) utility functions: $\mathrm{U}(c)=\mathrm{V}(c)=\left(c^{1-\alpha}-1\right) /(1-\alpha)$, where $\alpha>0$. Households are price takers in financial markets.

This simple model captures two important features of real-world economies. First, the timing of real income differs across households, providing an incentive for intertemporal trade. Second, future aggregate output is uncertain. In combination with income-timing differences, this uncertainty creates an incentive for risk sharing. I begin with an economy in which there are no barriers to state-contingent, intertemporal trade. Then, I consider monetary policy in an economy in which the only financial instrument is a nominal bond.

\section{$\underline{\text { Complete Capital Markets }}$}

Suppose that type-2 households are able to sell Arrow-style state-contingent securities to type-1 households. Each such security pays 1 unit of output should a particular period-2 state arise, and nothing otherwise. If $q_{i}$ denotes the quantity of security $i$ sold by a representative type-2 household and $s_{i}$ denotes its price, then

$$
\begin{array}{ll}
\frac{\text { Period } 1}{c_{1}(1)=\theta y(1)-q^{\prime} \bullet s} & \frac{\text { Period } 2}{c_{1}(2)=(1-\theta) y_{i^{*}}(2)+q_{i^{*}}} \\
c_{2}(1)=(1-\theta) y(1)+q^{\prime} \bullet s & c_{2}(2)=\theta y_{i^{*}}(2)-q_{i^{*}}
\end{array}
$$


where $q$ and $s$ are vectors whose $i^{\text {th }}$ elements are $q_{i}$ and $s_{i}$, respectively, and where $i^{*}$ is the realized state. Type-1 households maximize expected utility when:

$$
s_{i} \mathrm{U}^{\prime}\left[\theta y(1)-q^{\prime} \bullet s^{\prime}\right]=\rho p_{i} \mathrm{U}^{\prime}\left[(1-\theta) y_{i}(2)+q_{i}\right]
$$

for each $i$. Similarly, the first-order conditions for a type-2 household are:

$$
s_{i} \mathrm{~V}^{\prime}\left[(1-\theta) y(1)+q^{\prime} \cdot s\right]=\rho p_{i} \mathrm{~V}^{\prime}\left[\theta y_{i}(2)-q_{i}\right]
$$

for $i=1,2, \ldots, S$. These conditions require that the marginal rate of substitution between period-1 and period-2 consumption be equal across households for every possible output realization.

Equations 2 and 3 also imply that the ratio $V^{\prime}\left(c_{2}(2)\right) / \mathrm{U}^{\prime}\left(c_{1}(2)\right)$ of second-period marginal utilities is completely independent of the realized level of period-2 output. This result, in turn, implies that output risk is shared in equilibrium: If realized second-period output is high, the second-period consumption of both type- 1 and type-2 households must be high; and if realized output is low, the consumption of both types of household must suffer. Formally, we know that $c_{1}(2)+c_{2}(2)=y(2)$ and that $\mathrm{V}^{\prime}\left(c_{2}(2)\right) / \mathrm{U}^{\prime}\left(c_{1}(2)\right)$ is independent of $y(2)$. Log-differentiate these conditions to get $\left(c_{1} / y\right) \mathrm{d} c_{1} / c_{1}+\left(c_{2} / y\right) \mathrm{d} c_{2} / c_{2}=\mathrm{d} y / y$ and $\mathrm{Ad} c_{1} / c_{1}=\mathrm{Bd} c_{2} / c_{2}$, where all variables are evaluated at their period-2 values, and where $\mathrm{A} \equiv-c_{1} \mathrm{U}^{\prime \prime}\left(c_{1}\right) / \mathrm{U}^{\prime}\left(c_{1}\right)>0$ and $\mathrm{B} \equiv-c_{2} \mathrm{~V}^{\prime \prime}\left(c_{2}\right) / \mathrm{V}^{\prime}\left(c_{2}\right)>0$ measure the risk aversion of type- 1 and type- 2 households, respectively. Solving:

$$
\mathrm{d} c_{1} / c_{1}=\left[\mathrm{B} y /\left(\mathrm{A} c_{2}+\mathrm{B} c_{1}\right)\right](\mathrm{d} y / y) \quad \mathrm{d} c_{2} / c_{2}=\left[\mathrm{A} y /\left(\mathrm{A} c_{2}+\mathrm{B} c_{1}\right)\right](\mathrm{d} y / y) .
$$

Both $c_{1}(2)$ and $c_{2}(2)$ are, thus, increasing in $y(2)$. Moreover, it is readily verified that $\mathrm{d} c_{1} / c_{1}<\mathrm{d} y / y<$ $\mathrm{d} c_{2} / c_{2}$ if $\mathrm{A}>\mathrm{B}$ and $\mathrm{d} c_{2} / c_{2}<\mathrm{d} y / y<\mathrm{d} c_{1} / c_{1}$ if $\mathrm{B}>\mathrm{A}$ : The consumption of whichever type household is more risk averse will vary less than in proportion to output, while the consumption of whichever type household is less risk averse will vary more than in proportion to output. ${ }^{6}$ When households of both types are equally risk averse $(\mathrm{A}=\mathrm{B})$, the consumption of both will be proportional to output:

\footnotetext{
${ }^{6}$ Suppose, for example, that $\mathrm{A}>\mathrm{B}$. Then $\mathrm{d} c_{1} / c_{1}=\left\{\mathrm{B} y /\left[(\mathrm{A}-\mathrm{B}) c_{2}+\mathrm{B} y\right]\right\}(\mathrm{d} y / y)<\mathrm{d} y / y<\{[\mathrm{A} y /[\mathrm{A} y$ - $\left.\left.\left.(\mathrm{A}-\mathrm{B}) c_{1}\right)\right]\right\}(\mathrm{d} y / y)=\mathrm{d} c_{2} / c_{2}$.
} 
$\mathrm{d} c_{1} / c_{1}=\mathrm{d} c_{2} / c_{2}=\mathrm{d} y / y$.

In the case where all households have the same CRRA utility function $[\mathrm{U}(c)=\mathrm{V}(c)=$ $\left.\left(c^{1-\alpha}-1\right) /(1-\alpha)\right]$, equations 2 and 3 are readily solved for $q_{i}$ and $s_{i}$ :

$$
s_{i}=\rho p_{i}\left[y(1) / y_{i}(2)\right]^{\alpha} \quad q_{i}=y_{i}(2)(2 \theta-1) /(1+z)
$$

where $z \equiv \rho E\left\{[y(2) / y(1)]^{1-\alpha}\right\}>0$. Security i's price is higher the higher is the probability that state $i$ occurs and the lower is state-i output. The quantity of security $i$ sold is proportional to the amount of output in state $i$. In the limit as $\theta$ approaches $1 / 2$, the two types of household become indistinguishable and the incentive for trade in contingent claims disappears. Equilibrium consumption paths are obtained by substituting from equation 5 back into equation 1 :

Period 1

$\overline{c_{1}(1)=y(1)[\theta /(1+z)+(1-\theta)(z /(1+z))]}$ $c_{2}(1)=y(1)[(1-\theta) /(1+z)+\theta(z /(1+z))]$
Period 2

$$
\overline{c_{1}(2)=y(2)[\theta /(1+z)+(1-\theta)(z /(1+z))]}
$$$$
c_{2}(2)=y(2)[(1-\theta) /(1+z)+\theta(z /(1+z))] \text {. }
$$

Each household consumes the same fraction of period-2 output as of period-1 output, and the consumption of every household is sensitive to period-2 output. Output risk is shared.

\section{Nominal Debt Contracts and Monetary Policy}

The absence of complete state-contingent securities markets is an essential element in the debt-deflation story. The point of the analysis that follows is that if capital markets are, indeed, incomplete in the manner described by Fisher (and, arguably, as we observe to a considerable degree in the world around us), then optimal monetary policy does not generally take the form of a price-level target. In the CRRA utility case, it takes the form of a nominal-spending target.

Without loss of generality, set the period-1 price level equal to 1 . The monetary authority determines the period-2 price level, $\pi$, after observing $y(2){ }^{7}$ Let $D$ be the debt issued by each type2 household in period 1 , and let $R$ denote the (gross) nominal interest rate. Then:

\footnotetext{
${ }^{7}$ Real-world central banks obviously do not have complete control of the price level. I seek to determine how policymakers ought to exercise whatever price-level control they do have.
} 


$$
\begin{aligned}
& \frac{\text { Period } 1}{c_{1}(1)=\theta y(1)-D} \quad \frac{\text { Period } 2}{c_{1}(2)=(1-\theta) y(2)+D R / \pi} \\
& c_{2}(1)=(1-\theta) y(1)+D \quad c_{2}(2)=\theta y(2)-D R / \pi
\end{aligned}
$$

where the period-2 outcomes assume that $\theta y(2)>D R / \pi$, so that type-2 households (“debtors") are not driven into bankruptcy. This no-bankruptcy condition is discussed further, below. For now, simply note that it restricts the value of period-2 output relative to the real principal and interest due on outstanding debt.

Taking $R$ as given, type-1 households (“creditors") maximize utility when:

$$
\mathrm{U}^{\prime}[\theta y(1)-D]=\rho R \mathrm{E}\left\{\mathrm{U}^{\prime}[(1-\theta) y(2)+D R / \pi] / \pi\right\} .
$$

Similarly, the first-order condition for each debtor is:

$$
\mathrm{V}^{\prime}[(1-\theta) y(1)+D]=\rho R \mathrm{E}\left\{\mathrm{V}^{\prime}[\theta y(2)-D R / \pi] / \pi\right\} .
$$

These two equations determine $D$ and $R$ conditional on the policy rule of the monetary authority and the probability distribution of period-2 output.

From equation 7 it's immediately clear that white-noise variation in the price level is bad: It creates fluctuations in the period-2 consumption of both creditors and debtors, reducing expected period-2 utility by Jensen's inequality. From this result, proponents of price-level targeting conclude that $\pi$ should be fixed in advance. With $\pi$ pre set, however, debtors' second-period consumption varies more than in proportion to output, while creditor's second-period consumption varies less than in proportion to output. In the extreme case where $\theta=1$, creditors are completely insulated from output risk while debtors are residual claimants on output. The monetary authority can spread output risk more evenly across debtors and creditors by varying the future price level systematically with future output, raising $\pi$ when $y(2)$ is low and lowering $\pi$ when $y(2)$ is high.

Suppose, for example, that the monetary authority targets the nominal value of period-2 output, $\pi y(2)$. With $\pi y(2)$ set equal to a pre-announced number, $n *$, equation 7 becomes: 


\begin{tabular}{|c|c|}
\hline Period 1 & Period 2 \\
\hline$c_{1}(1)=\theta y(1)-D$ & $c_{1}(2)=\left(1-\theta+D R / n^{*}\right) y(2)$ \\
\hline$c_{2}(1)=(1-\theta) y(1)+D$ & $c_{2}(2)=\left(\theta-D R / n^{*}\right) y(2)$ \\
\hline
\end{tabular}

while equations 8 and 9 reduce to

$$
\mathrm{U}^{\prime}[\theta y(1)-D]=\left(\rho R / n^{*}\right) \mathrm{E}\left\{y(2) \mathrm{U}^{\prime}\left[\left(1-\theta+D R / n^{*}\right) y(2)\right]\right\}
$$

and

$$
\mathrm{V}^{\prime}[(1-\theta) y(1)+D]=\left(\rho R / n^{*}\right) \mathrm{E}\left\{y(2) \mathrm{V}^{\prime}\left[\left(\theta-D R / n^{*}\right) y(2)\right]\right\},
$$

respectively. Note that the period-2 consumption of both creditors and debtors is now proportional to period-2 output.

If households share the same CRRA utility function $\left[\mathrm{U}(c)=\mathrm{V}(c)=\left(c^{1-\alpha}-1\right) /(1-\alpha)\right]$, the household first-order conditions (equations 8' and 9') are satisfied if, and only if,

$$
D=y(1)(2 \theta-1)[z /(1+z)]
$$

and

$$
R=\left[n^{*} / y(1)\right] / z,
$$

where, as before, $z \equiv \rho E\left\{[y(2) / y(1)]^{1-\alpha}\right\}>0$. Equations 10 and 11 say that lending is proportional to period-1 output and that the nominal interest rate is proportional to the growth rate of nominal income, respectively. Total nominal debt payments are $D R=n^{*}(2 \theta-1) /(1+z)$, real debt payments are $D R / \pi=y(2)(2 \theta-1) /(1+z)$, and the ex post real interest rate is $R / \pi=[y(2) / y(1)] / z$. When these expressions are substituted into equation 7', the implied allocation of consumption across households and across time is identical to that obtained when capital markets are complete (equation 6). Thus, an economy with nominal debt contracts allocates aggregate output risk every bit as efficiently as an economy with a complete set of state-contingent securities, provided that the monetary authority targets nominal income.

Importantly, the no-bankruptcy condition is always satisfied under nominal-income targeting: Recalling that $z>0$ and $1 \geq \theta>1 / 2$, we have $D R / \pi=y(2)(2 \theta-1) /(1+z)<y(2)(2 \theta-1) \leq$ $\theta y(2)$. Under a price-level target, in contrast, debtors' second-period incomes, $\theta y(2)$, will fall 
below their real debt obligations, $D R / \pi$, if realized period-2 output is sufficiently low. So, explicit bankruptcy costs would only serve to enhance the attractiveness of nominal-income targeting relative to price-level targeting. (An analysis of price-level targeting that takes bankruptcy into account is presented in an appendix.)

\section{$\underline{\text { Implications }}$}

The above analysis has potentially important implications for credit rationing, for policy and policy evaluation, and for empirical assessments of nominal debt’s recession role.

As previously noted, the no-bankruptcy condition is automatically satisfied if the monetary authority fixes nominal income in advance. This result suggests that limits on credit are not likely to be exogenous (contrary to Eggertsson and Krugman 2011): They will depend on the policy rule that people believe is being followed by the monetary authority.

On policy, the above analysis suggests that in order to facilitate efficient risk sharing, central banks ought to minimize nominal-income surprises - where a "surprise" is any movement not anticipated when current nominal debt contracts were negotiated. ${ }^{8}$ Variants of nominal-income targeting that try to stabilize income forecasts (e.g., Hall and Mankiw 1994) do not meet this criterion. Variants that make the nominal income target contingent on recent information will also be unsatisfactory from a risk-sharing perspective. Policies that seek to stabilize short-horizon income growth, because they make the current target income level contingent on a recent income realization, fall into this category. Also in this category are policies that make the current target income level or growth rate contingent on the latest estimates of the amount of slack in the economy (Hall 1984, McCallum and Nelson 1999a). Rules that depend on the deviation of output from trend output may allocate risk well, however, if the estimated trend is not sensitive to recent data. ${ }^{9}$ Similarly, rules that depend on realized growth in the price level and/or output may be

${ }^{8}$ Doepke and Schneider (2006a) document that the average duration of non-financial, privatesector nominal liabilities is on the order of 3-to-5 years. To facilitate efficient risk sharing, the Federal Reserve would need to commit to a target path for nominal income extending out at least that far.

${ }^{9}$ For example, a rule which requires that the central bank equate period- $t$ nominal income, $n(t) \equiv$ $p(t)+y(t)$, to $n^{*}(t)=p(t-T)+T \pi^{*}+\mathrm{E}_{t-T} y^{*}(t)$ - where $p(t)$ and $y(t)$ are the logarithms of the price level and output at time $t, \pi^{*}$ is the desired long-run inflation rate, $y^{*}(t)$ is the log of time-t potential output, and $\mathrm{E}_{t-T}$ is the mathematical expectation conditional on information at $t-T$-will allocate risk efficiently provided that $T$ is sufficiently large. In practice, to keep nominal income on track the central bank might 
acceptable, if growth is calculated over a sufficiently long horizon. The point is that there is a fairly wide variety of policy rules consistent with efficient risk sharing: Nominal-income targeting need not mean "setting and forgetting" a target income path.

Most simulation studies ignore the role that monetary policy plays in allocating risk, so their conclusions about the relative performance of alternative policy rules are suspect. ${ }^{10}$ In economies with nominal debt contracts, importantly, it is not just price and output variability that matter for performance (the "Taylor curve”), but also the correlation between price and output fluctuations.

Finally, several commentators have expressed skepticism about the significance of debt deflation’s role in the 2008-2009 “Great Recession” based on the relatively small decline in inflation over the course of the downturn. ${ }^{11}$ This note has argued, though, that the financial stress resulting from fixed nominal debt obligations is due as much to adverse real-income shocks as it is to adverse inflation shocks: Fisher's “debt deflation” story is incomplete. Although the role of debt deflation narrowly defined may have been limited in the Great Recession, financial strain placed on borrowers as a result of fixed nominal debt may, nevertheless, have contributed substantially to the downturn's severity.

\section{Empirical Evidence}

If the story told here is correct, there ought to be a stronger negative correlation between nominal-income growth surprises and measures of financial stress than there is between pricegrowth surprises and the same measures of stress. Chart 1 presents supporting evidence.

The top panel of the chart shows the 5-quarter change in the loan-delinquency rate for

raise or lower the short-term interest rate depending on whether income is above or below target:

$$
\dot{R}(t)=\tau \times\left[n(t)-n^{*}(t)\right]=\tau \times\left\{\left[p(t)-p(t-T)-T \pi^{*}\right]+\left[y(t)-\mathrm{E}_{t-T} y^{*}(t)\right]\right\},
$$

where $\tau>0$ is a parameter that measures policy aggressiveness. The only difference between this rule and a standard Taylor rule is that the latter sets $T=1$.

${ }^{10}$ Examples of simulation studies to which this criticism applies include (among many others) McCallum and Nelson (1999b) and Rudebusch (2002).

${ }^{11}$ See Eichenbaum (2011) and Hall (2011). Similarly, based on the timing of declines of output and prices, Carlstrom and Fuerst (2001) argue that debt deflation explains little of the Great Depression. 
commercial banks, plotted on an inverted scale, along with the surprise component of 5-quarter nominal GDP growth. The latter variable is calculated as the difference between actual 5-quarter growth in nominal GDP and the 5-quarter growth predicted by participants in the Federal Reserve Bank of Philadelphia's Survey of Professional Forecasters (SPF). ${ }^{12}$ There is a strong tendency for the loan-delinquency rate to rise when nominal GDP growth disappoints. (The correlation between the two series is -0.64.) The tightness of the relationship between nominal GDP surprises and the loan-delinquency rate during and in the lead-up to the recent recession is especially striking.

The bottom panel shows the same loan-delinquency rate as before, but this time plotted with the surprise component of 5-quarter GDP price inflation. The correlation here is much lower than in the top panel (only -0.10). So, indeed, nominal-income surprises appear to be more closely related to financial distress than are price surprises.

A regression of the change in the delinquency rate on nominal-income-growth and pricegrowth surprises yields the following results:

$$
\begin{aligned}
& \Delta \delta=-0.309\left[\left(\Delta y-\Delta y^{\mathrm{e}}\right)+\left(\pi-\pi^{\mathrm{e}}\right)\right]+0.086\left(\pi-\pi^{\mathrm{e}}\right) \quad \text { Adj. } R^{2}=0.401 \\
& (0.077) \quad(0.131) \quad \text { S.E. }=0.813
\end{aligned}
$$

where $\Delta \delta$ is the 5-quarter change in the delinquency rate, $\left(\Delta y-\Delta y^{\mathrm{e}}\right)$ is the surprise component of 5quarter real GDP growth, and $\left(\pi-\pi^{e}\right)$ is the surprise component of 5-quarter GDP inflation.

Newey-West-corrected standard errors are reported in parentheses below the coefficient estimates. One cannot reject the hypothesis that real-growth and inflation surprises have equal effects on the loan delinquency rate-i.e., it is only nominal GDP surprises that matter for the delinquency rate. The coefficient on nominal-GDP-growth surprises has a $P$ value of $0.0001 .^{13}$

${ }^{12}$ Delinquency data back to 1985:Q1 are available on the Board of Governors' website. SPF data are available on the website of the Federal Reserve Bank of Philadelphia. The SPF is conducted one month into each 5-quarter period. At that point, survey participants have an official estimate of the prior quarter's nominal GDP. The longest SPF forecast horizon consistently available extends four quarters beyond the survey quarter.

${ }^{13}$ Very similar results are obtained using the "junk-bond spread" (the difference between the yields on below-investment-grade and high-quality corporate bonds) or the "excess bond premium" in place of changes in the loan-delinquency rate. For example, the correlation between the junk-bond spread and the surprise in nominal GDP growth over the prior five quarters is -0.63 over a 1985:Q1-to-2011:Q1 sample, while the correlation with surprise inflation is only -0.04 . For the excess bond premium (with 


\section{Concluding Remarks}

If there are complete markets in contingent claims, so that agents can insure themselves against fluctuations in aggregate output and the price level, then "money is a veil” as far as the allocation of risk is concerned: It doesn't matter whether the monetary authority allows random variation in the price level or nominal value of output. If such insurance is not available, monetary policy will affect the allocation of risk. When debt obligations are fixed in nominal terms, a pricelevel target eliminates one source of risk (price-level shocks), but shifts the other risk (real output shocks) disproportionately onto debtors. A more balanced risk allocation is achieved by allowing the price level to move opposite to real output. An example is presented in which the risk allocation achieved by a nominal-income target reproduces exactly the allocation observed with complete capital markets. Empirically, measures of financial stress are much more strongly related to nominal-GDP surprises than to inflation surprises. These theoretical and empirical results call into question the debt-deflation argument for a price-level or inflation target. More generally, they point to the danger of evaluating alternative monetary policy rules using representative-agent models that have no meaningful role for debt.

data back to 1973:Q1) the comparable correlations are -0.40 and -0.04 , respectively. Movements in the junk-bond spread reflect changes in the default risk on lower-quality bonds and, more broadly, are thought to capture changes in the external finance premium-a key indicator of overall credit conditions (Gertler and Lown 1999; Mody and Taylor 2003). The excess bond premium is a new measure of the price of bond-market risk developed from micro-level data by Gilchrist and Zakrajsek (forthcoming). 


\section{Appendix: Price-Level Targeting with the Possibility of Bankruptcy}

Overview: We have argued that in economies with simple nominal debt contracts, nominal-income targeting - because of the way in which it spreads risk - reduces the chances that debtors will be driven into bankruptcy by aggregate output fluctuations. In the stylized model of the main text, the threat of bankruptcy is completely eliminated. Under a price-level or inflation target, in contrast, aggregate output risk is disproportionately borne by debtors. This risk concentration is inefficient. The obvious caveat is that creditors avoid output risk only if output shocks are not so large as to drive debtors into bankruptcy. Bankruptcy shifts risk back onto lenders, and it is reasonable to ask whether in an economy with large output fluctuations it is possible to structure bankruptcy so that the efficient allocation is recovered. This appendix argues that the answer to this question is "no". Each borrower, knowing that his consumption in the event of bankruptcy will, at the margin, be independent of the amount owed, sees a distorted (understated) cost of taking on debt. As far as borrowers are concerned, in the event of default it's "in for a penny, in for a pound". The result is an excess demand for loans at the interest rate that calls forth the optimal supply of loans. In equilibrium debt and/or the interest rate are too high, and risk is not efficiently distributed.

Formal Analysis: The analytical framework is the same as that used in the main text, in the discussion of nominal debt contracts, except simplified further by assuming that $\theta=1$ (so that the difference in the timing of income is extreme) and that period-2 output takes on only two possible values, "low" $\left(y_{L}\right)$ and "high" $\left(y_{H}\right)$, with probabilities $p_{L}$ and $p_{H}=1-p_{L}$ respectively. (Introducing additional states would only make it more difficult to approximate the efficient equilibrium.) In the case of interest, debtors are forced into bankruptcy when period-2 output is low.

Without loss of generality, assume that the monetary authority targets a constant price level (equivalently, a zero inflation rate), announcing in advance that it will hold $\pi=1$. The typical type-2 household will then choose its level of borrowing, $D$, so as to maximize $\mathrm{V}(D)+\rho\left[p_{H} \mathrm{~V}\left(y_{H}-D R\right)+p_{L} \mathrm{~V}(\beta)\right]$, where $0<\beta<y_{L}$ is the level of consumption that the law allows bankrupts. Taking $R$ and $\beta$ as given, the household takes on debt until the net marginal utility of debt equals zero:

$$
\mathrm{V}^{\prime}(D)-\rho R p_{H} \mathrm{~V}^{\prime}\left(y_{H}-D R\right)=0 .
$$

The typical type-1 household, meanwhile, chooses its level of lending, $L$, so as to maximize $\mathrm{U}[y(1)-L]+$ $\rho\left\{p_{H} \mathrm{U}(L R)+p_{L} \mathrm{U}\left[\left(y_{L}-\beta\right) L / D\right]\right\}$, where $D$ is the average level of type-2 household indebtedness. Note that in the bankruptcy state, each creditor household receives a settlement that is proportional to the volume of its lending: Type- 1 households may receive a low marginal return in the event of bankruptcy, but they don't receive a zero return. Taking $R, \beta$ and $D$ as given, the representative lender maximizes utility when

$$
\rho R p_{H} \mathrm{U}^{\prime}(L R)+\rho\left[\left(y_{L}-\beta\right) / D\right] p_{L} \mathrm{U}^{\prime}\left[\left(y_{L}-\beta\right) L / D\right]-\mathrm{U}^{\prime}[y(1)-L]=0
$$

The bond market clears in equilibrium, so that A.2 becomes:

$$
\rho R p_{H} \mathrm{U}^{\prime}(D R)+\rho\left[\left(y_{L}-\beta\right) / D\right] p_{L} \mathrm{U}^{\prime}\left(y_{L}-\beta\right)-\mathrm{U}^{\prime}[y(1)-D]=0 .
$$

We want to see whether it is possible to achieve an efficient allocation of risk in this economy. With complete contingent claims, each type- 1 household consumes $q_{L}$ in period 2 if the low-output state is realized, while type- 2 households each consume $y_{L}-q_{L}$, (c.f. equation 1 in the main text). Accordingly, suppose that $\beta$ is set equal to $y_{L}-q_{L}$. The first-order condition for lenders becomes:

$$
\rho R p_{H} \mathrm{U}^{\prime}(D R)+\rho\left(q_{L} / D\right) p_{L} \mathrm{U}^{\prime}\left(q_{L}\right)-\mathrm{U}^{\prime}[y(1)-D]=0 .
$$


In the efficient equilibrium we also know that $c_{1}(2)=q_{H}$ in the event that the high-output state is realized in period 2, and that $c_{1}(1)=y(1)-\left(q_{L} s_{L}+q_{H} s_{H}\right)$, where $s_{L}$ and $s_{H}$ satisfy

$$
s_{i} \mathrm{U}^{\prime}\left[y(1)-\left(q_{L} s_{L}+q_{H} s_{H}\right)\right]=\rho p_{i} \mathrm{U}^{\prime}\left(q_{i}\right)
$$

for $i=L, H$. (See equations 1 and 2 in the main text.) It is readily verified that to achieve the completemarkets equilibrium consumption levels in our nominal-debt economy one must have

and

$$
R=q_{H} /\left(q_{L} s_{L}+q_{H} s_{H}\right) \quad \text { A.3 }
$$

$$
D=q_{L} s_{L}+q_{H} s_{H},
$$

and that these conditions are consistent with A.2". However, when A.3 and A.4 are substituted into the lefthand side of A.1 one finds:

$$
\begin{aligned}
\mathrm{V}^{\prime}(D)-\rho R p_{H} \mathrm{~V}^{\prime}\left(y_{H}-D R\right) & =\mathrm{V}^{\prime}\left(q_{L} s_{L}+q_{H} s_{H}\right)-\rho\left[q_{H} p_{H} /\left(q_{L} s_{L}+q_{H} s_{H}\right)\right] \mathrm{V}^{\prime}\left(y_{H}-q_{H}\right) \\
& =\mathrm{V}^{\prime}\left(q_{L} s_{L}+q_{H} s_{H}\right)-\left[q_{H} s_{H} /\left(q_{L} s_{L}+q_{H} s_{H}\right)\right] \mathrm{V}^{\prime}\left(q_{L} s_{L}+q_{H} s_{H}\right) \\
& =\left[q_{L} s_{L} /\left(q_{L} s_{L}+q_{H} s_{H}\right)\right] \mathrm{V}^{\prime}\left(q_{L} s_{L}+q_{H} s_{H}\right)>0 .
\end{aligned}
$$

(Here, the second line follows from equation 3 in the main text.) Equation A.1' implies that at the interest rate given in equation A.3, type-2 households want to borrow more than the amount given by equation A.4: There is excess demand for credit. Again, the intuition is that because type-2 households' bankruptcy

\begin{tabular}{|c|c|c|}
\hline$q_{L}=y_{L} /(1+\rho)$ & $q_{H}=y_{H} /(1+\rho)$ & \\
\hline$s_{L}=\rho p_{L} y(1) / y_{L}$ & $s_{H}=\rho p_{H} y(1) / y_{H}$ & \\
\hline$c_{1}(1)=y(1) /(1+\rho)$ & $\begin{aligned} c_{1}(2) & =y_{L} /(1+\rho) \\
& =y_{H} /(1+\rho)\end{aligned}$ & $\begin{array}{l}\text { if } y(2)=y_{L} \\
\text { if } y(2)=y_{H}\end{array}$ \\
\hline$c_{2}(1)=y(1) \rho /(1+\rho)$ & $\begin{aligned} c_{2}(2) & =y_{L} \rho /(1+\rho) \\
& =y_{H} \rho /(1+\rho)\end{aligned}$ & $\begin{array}{l}\text { if } y(2)=y_{L} \\
\text { if } y(2)=y_{H}\end{array}$ \\
\hline
\end{tabular}
settlements are independent of their level of borrowing, they have an incentive to take on too much debt. The result is that the credit market clears at a higher interest rate and/or higher level of debt than is consistent with achieving the complete-markets equilibrium allocation.

\begin{tabular}{|c|c|c|}
\hline$D=y(1) \rho /(1+\rho)$ & $\begin{aligned} R / \pi & =(1 / \rho)\left[y_{L} / y(1)\right] \\
& =(1 / \rho)\left[y_{H} / y(1)\right]\end{aligned}$ & $\begin{array}{l}\text { if } y(2)=y_{L} \\
\text { if } y(2)=y_{H}\end{array}$ \\
\hline$c_{1}(1)=y(1) /(1+\rho)$ & $\begin{aligned} c_{1}(2) & =y_{L} /(1+\rho) \\
& =y_{H} /(1+\rho)\end{aligned}$ & $\begin{array}{l}\text { if } y(2)=y_{L} \\
\text { if } y(2)=y_{H}\end{array}$ \\
\hline$c_{2}(1)=y(1) \rho /(1+\rho)$ & $\begin{aligned} c_{2}(2) & =y_{L} \rho /(1+\rho) \\
& =y_{H} \rho /(1+\rho)\end{aligned}$ & $\begin{array}{l}\text { if } y(2)=y_{L} \\
\text { if } y(2)=y_{H} .\end{array}$ \\
\hline
\end{tabular}

Example: With $\mathrm{U}(c)=\mathrm{V}(c)=\log (c)$ the equilibrium for an economy with contingent claims takes the form:

Equilibrium with Complete Contingent Claims

(See equations 5 and 6 in the main text, with $\alpha=1$.) Exactly the same equilibrium output allocation is achievable with nominal-debt contracts, provided that the monetary authority targets nominal income:

(See equations 7', 10 and 11 in the main text, with $\alpha=1$.)

With nominal debt and a price-level target $\left(\pi=\pi^{*} \equiv 1\right)$, equations 7 and 8 in the main text imply: 
Equilibrium with Nominal Debt and a Price-Level Target: The No-Bankruptcy Case

$$
\begin{aligned}
& D=y(1) \rho /(1+\rho) \\
& c_{1}(1)=y(1) /(1+\rho) \\
& c_{2}(1)=y(1) \rho /(1+\rho)
\end{aligned}
$$

$R$ [see A.5 and A.7, below]

$c_{1}(2)=D R$ [see A.5 and A.6, below]

$c_{2}(2)=y_{L}-D R \quad$ if $y(2)=y_{L}$

$=y_{H}-D R$

if $y(2)=y_{H}$,

provided that output fluctuations are not so large as to trigger debtor bankruptcy. From equation 9, the output that each creditor receives in the second period is the solution to the equation

$$
D R=(1 / \rho)\left(y_{L}-D R\right)\left(y_{H}-D R\right) /\left[p_{H}\left(y_{L}-D R\right)+p_{L}\left(y_{H}-D R\right)\right] \text {. }
$$

The equilibrium interest rate is then found by dividing $D R$ by $y(1) \rho /(1+\rho)$.

Note that $\left(y_{H}-D R\right)>p_{H}\left(y_{L}-D R\right)+p_{L}\left(y_{H}-D R\right)>\left(y_{L}-D R\right)$. Substitute into the denominator of equation A.5 to obtain

$$
y_{L} /(1+\rho)<D R<y_{H} /(1+\rho) .
$$

The fixed second-period consumption of creditors is an average of what they would have consumed in an economy with complete markets. Output risk is borne entirely by debtors. Equivalently,

$$
(1 / \rho)\left[y_{L} / y(1)\right]<R<(1 / \rho)\left[y_{H} / y(1)\right] \text {. }
$$

The equilibrium interest rate in the no-bankruptcy case is a compromise between the ex post real rates observed under nominal-income targeting.

Bankruptcy will be a non-issue if debtors always have enough second-period income to meet their obligations. Since $y_{H} /(1+\rho)>D R$ in an economy with nominal debt and a price-level target, to rule out bankruptcy it is sufficient that $y_{L} \geq y_{H} /(1+\rho)$. If, however, output fluctuations are large enough that bankruptcy can't be ruled out, we must turn to equations A.1 and A.2' to find the economy's equilibrium:

Equilibrium with Nominal Debt and a Price-Level Target: Contingent Bankruptcy

$$
\begin{array}{lrlrl}
D=y(1) \rho /(1+\rho) & R=(1 / \rho)\left[y_{H} / y(1)\right]\left[(1+\rho) /\left(1+\rho p_{H}\right)\right] \\
c_{1}(1)=y(1) /(1+\rho) & c_{1}(2)=y_{L}-\beta & & \text { if } y(2)=y_{L} \\
& & =y_{H} /\left(1+\rho p_{H}\right) & & \text { if } y(2)=y_{H} \\
c_{2}(1)=y(1) \rho /(1+\rho) & c_{2}(2) & =\beta & & \text { if } y(2)=y_{L} \\
& & =y_{H}\left[\rho p_{H} /\left(1+\rho p_{H}\right)\right] & \text { if } y(2)=y_{H} .
\end{array}
$$

For any given first-period income, $y(1)$, the level of debt is the same as in the nominal-income-targeting and no-bankruptcy cases already examined. However, creditors must now be compensated for default risk, so the equilibrium interest rate is higher than in these cases for any given $y_{H} / y(1)$. As a result, the fraction of output that goes to creditors in the good state is too large to be consistent with optimal risk sharing.

Summary: Risk is inefficiently allocated in an economy with simple nominal debt contracts and price-level targeting. If output variation is small enough that debtors always have the means to meet their obligations, then creditors are excessively insulated from output risk while the consumption of debtors is excessively sensitive to output. If output variation is large, then debtors may be forced into bankruptcy in the event of a poor output realization. The fact that each debtor's consumption in the bankruptcy state is independent of his level of indebtedness encourages over-borrowing and drives up equilibrium debt and/or the equilibrium interest rate. As a result, there is a larger-than-optimal transfer to creditors when bankruptcy fails to occur. 


\section{Appendix: Price-Level Targeting with Tiered Debt}

Overview: In an economy with simple nominal debt contracts, we've seen that price-level targeting distributes risk inefficiently. Not surprisingly, it is possible to recover the efficient equilibrium if debt contracts are allowed to be more sophisticated. In particular, recovering the efficient equilibrium is possible when there are as many tiers (seniority levels) of debt as there are second-period output states.

Formal Analysis: Basic assumptions are the same as in the main text: a two-period endowment economy in which second-period output can take on any of $S$ possible values each with known probability; two types of household, distinguished by the timing of their endowments; and tastes that can be represented by wellbehaved, time-separable utility functions. To hold down notational complexity, the parameter $\theta$, which governs the timing of consumption, is set equal to 1 . Also, without loss of generality, it will be assumed that the monetary authority sets the second-period price level, $\pi$, equal to 1 .

Suppose there are $S$ types of debt. Tier- 1 debt is the most senior: it pays off in every state. Tier- 2 debt is next most senior, and is forgiven only in the very worst state $\left[y(2)=y_{1}(2)\right]$. At the other extreme, tier$S$ debt (the most junior) is forgiven in all but the very best state $\left[y(2)=y_{s}(2)\right]$. Consumption levels are:

\begin{tabular}{|c|c|}
\hline Period 1 & Period 2 \\
\hline $\begin{array}{l}{ }_{1}(1)=y(1)-\Sigma_{i} D_{i} \\
{ }_{2}(1)=\Sigma_{i} D_{i}\end{array}$ & $\begin{array}{l}c_{1}(2)=D_{1} R_{1}+D_{2} R_{2}+\ldots+D_{i^{*}} R_{i^{*}} \\
c_{2}(2)=y_{i^{*}}(2)-\left[D_{1} R_{1}+D_{2} R_{2}+\ldots+D_{i^{*}} R_{i^{*}}\right]\end{array}$ \\
\hline
\end{tabular}

where $i^{*}$ is the realized state, $D_{i}$ is the quantity of tier- $i$ debt sold in period 1 , and $R_{i}$ is the (gross) return on tier- $i$ debt. The first-order conditions for type- 1 and type- 2 households are

$$
\begin{aligned}
& \begin{aligned}
\mathrm{U}^{\prime}[y(1)- & \left.\Sigma_{j} D_{j}\right]= \\
& \rho R_{i}\left[p_{i} \mathrm{U}^{\prime}\left(D_{1} R_{1}+\ldots+D_{i} R_{i}\right)+p_{i+1} \mathrm{U}^{\prime}\left(D_{1} R_{1}+\ldots+D_{i+1} R_{i+1}\right)+\ldots\right. \\
& \left.+p_{S} \mathrm{U}^{\prime}\left(D_{1} R_{1}+\ldots+D_{S} R_{S}\right)\right]
\end{aligned} \\
& \begin{aligned}
\mathrm{V}^{\prime}\left(\Sigma_{j} D_{j}\right)= & \rho R_{i}\left\{p_{i} \mathrm{~V}^{\prime}\left[y_{i}(2)-\left(D_{1} R_{1}+\ldots+D_{i} R_{i}\right)\right]+p_{i+1} \mathrm{~V}^{\prime}\left[y_{i+1}(2)-\left(D_{1} R_{1}+\ldots+D_{i+1} R_{i+1}\right)\right]+\ldots\right. \\
& \left.+p_{S} \mathrm{~V}^{\prime}\left[y_{S}(2)-\left(D_{1} R_{1}+\ldots+D_{S} R_{S}\right)\right]\right\}
\end{aligned}
\end{aligned}
$$

for $i=1,2, \ldots, S$, respectively.

To see that the equilibrium of this economy is identical to that described in the main text (equations 1-3) for an economy with complete markets in contingent claims, simply let

$$
\begin{aligned}
& D_{i}=q_{1}\left(s_{1}+s_{2}+\ldots+s_{S}\right) \quad \text { for } i=1 \\
& =\left(q_{i}-q_{i-1}\right)\left(s_{i}+s_{i+1}+\ldots+s_{S}\right) \text { for } i=2,3, \ldots, S \\
& R_{i}=1 /\left(s_{i}+s_{i+1}+s_{i+2}+\ldots+s_{S}\right) \quad \text { for } i=1,2, \ldots, S
\end{aligned}
$$

and substitute into equations B.1-B.3, to verify that they are satisfied. Here $q_{i}$ and $s_{i}$ are the equilibrium quantity and price of the $i^{\text {th }}$ Arrow-style contingent claim, respectively. Because $q_{i}>q_{i-1}$ (p. 4 of the main text), each $D_{i}>0$. Also—as one would expect—-the greater a bond issue's seniority, the lower its yield.

Remarks: Note that the equilibrium allows debtors to "walk away" from obligations even though they may be perfectly able to pay some — or even all—of them. For example, suppose that utility is logarithmic, and suppose that the worst possible period-2 state is realized $\left(i^{*}=1\right)$, so that only the most senior debt must be paid. Then $c_{1}(2)=c_{2}(2)=y_{1}(2) / 2$, and the total amount of principal and interest forgiven is $\left[y_{s}(2)-y_{1}(2)\right] / 2$. As long as $y_{1}(2)>y_{s}(2) / 2$ debtors have the wherewithal to meet all of their obligations - they are simply not required to do so. This treatment is much more generous than that which we observe in the real world, where tiering's role is limited to determining the order in which debts are discharged in bankruptcy. 


\section{References}

Ball, Laurence (1997) “Efficient Rules for Monetary Policy,” NBER Working Paper \#5952.

Bean, Charles R. (1983) “Targeting Nominal Income: An Appraisal,” Economic Journal 93, 80619.

Bernanke, Ben S. (1995) “The Macroeconomics of the Great Depression: A Comparative Approach,” Journal of Money, Credit, and Banking 27, No. 1, 1-28.

(2003) “Some Thoughts on Monetary Policy in Japan,” speech before the Japan Society of Monetary Economics: Tokyo, May 31.

Bohn, Henning (1988) “Why Do We Have Nominal Government Debt?” Journal of Monetary Economics 21, 127-140.

(2009) “Intergenerational Risk Sharing and Fiscal Policy” Journal of Monetary Economics $56,805-816$.

Carlstrom, Charles T. and Timothy S. Fuerst (2001) "Perils of Price Deflations: An Analysis of the Great Depression” Federal Reserve Bank of Cleveland Economic Commentary (February 15).

Crawford, Allan, Cesaire A. Meh, and Yaz Terajima (2009) "Price-Level Uncertainty, Price-Level Targeting, and Nominal Debt Contracts,” Bank of Canada Review, Spring, 31-41.

Doepke, Matthias and Martin Schneider (2006a) "Inflation and the Redistribution of Nominal Wealth,” Journal of Political Economy 114, 1069-1097.

(2006b) “Inflation as a Redistribution Shock: Effects on Aggregates and Welfare,” NBER Working Paper \#12319.

Eggertsson, Gauti B. and Paul Krugman (2011) "Debt, Deleveraging, and the Liquidity Trap: A Fisher-Minsky-Koo Approach,” unpublished manuscript presented February 25, 2011 at the Federal Reserve Bank of San Francisco conference on Monetary Policy at the Zero Lower Bound.

Eichenbaum, Martin (2011) “Discussion of Eggertsson and Krugman’s ‘Debt, Deleveraging, and the Liquidity Trap”” presented February 25, 2011 at the Federal Reserve Bank of San Francisco conference on Monetary Policy at the Zero Lower Bound.

Fisher, Irving (1933) “The Debt-Deflation Theory of Great Depressions,” Econometrica 1, 337-357.

Gertler, Mark and Cara Lown (1999) "The information content of the high yield bond spread for the business cycle,” Oxford Review of Economic Policy 15, 132-150. 
Gilchrist, Simon and Egon Zakrajsek (forthcoming) "Credit Spreads and Business Cycle Fluctuations," American Economic Review.

Hall, Robert E. (1984) "Monetary Strategy with an Elastic Price Standard” in Price Stability and Public Policy, A Symposium Sponsored by the Federal Reserve Bank of Kansas City (Kansas City: Federal Reserve Bank of Kansas City), 137-159.

(2011) “Discussion of Eggertsson and Krugman's 'Debt, Deleveraging, and the Liquidity Trap’” presented February 25, 2011 at the Federal Reserve Bank of San Francisco conference on Monetary Policy at the Zero Lower Bound.

Hall, Robert E. and N. Gregory Mankiw (1994) "Nominal Income Targeting” in Mankiw (editor), Monetary Policy (Chicago: University of Chicago Press for the NBER), 71-93.

Koenig, Evan F. (1995) “Optimal Monetary Policy in an Economy with Sticky Nominal Wages,” Federal Reserve Bank of Dallas Economic Review (2), 24-31. (1996) “Targeting Nominal Income: A Closer Look,” Economics Letters 51, 89-93. (2005) “Optimal Monetary Policy in Economies with 'Sticky-Information’ Wages,” Federal Reserve Bank of Dallas Working Paper \#0405.

Mankiw, N. Gregory and Ricardo Reis (2002), "Sticky Information Versus Sticky Prices: A Proposal to Replace the New Keynesian Phillips Curve, ” Quarterly Journal of Economics 117(4), 1295-1328.

McCallum, Bennett T. (1984) "Monetarist Rules in the Light of Recent Experience," American Economic Review Papers and Proceedings 74, 388-391.

(1997) “The Alleged Instability of Nominal Income Targeting” NBER Working Paper \#6291.

McCallum, Bennett T. and Edward Nelson (1999a) "Nominal Income Targeting in an OpenEconomy Optimizing Model,” Journal of Monetary Economics 43, 553-578.

(1999b) "Performance of Operational Policy Rules in an Estimated Semi-Classical Structural Model,” in John B. Taylor (editor) Monetary Policy Rules (Chicago: University of Chicago Press for the NBER), 15-45.

Meade, James E. (1978) “The Meaning of Internal Balance,” Economic Journal 91, 423-435.

Mody, Ashoka and Mark P. Taylor (2003) "The high-yield spread as a predictor of real economic activity: Evidence of a financial accelerator for the United States,” IMF Staff Papers 50(3), 373402.

Rudebusch, Glenn D. (2002) “Assessing Nominal Income Rules for Monetary Policy with Model and Data Uncertainty” Economic Journal 112, 402-432. 




\section{CHART 1B. Loan delinquency-rate changes only weakly related to unexpected inflation.}

$5 Q$ annualized growth



